\title{
Posterior composite restoration update: focus on factors influencing form and function
}

This article was published in the following Dove Press journal:

Clinical, Cosmetic and Investigational Dentistry

14 May 2013

Number of times this article has been viewed

\author{
Brenda S Bohaty ${ }^{1,2}$ \\ Qiang $\mathrm{Ye}^{3}$ \\ Anil Misra ${ }^{3,4}$ \\ Fabio Sene ${ }^{6}$ \\ Paulette Spencer ${ }^{3,5}$ \\ 'Department of Pediatric Dentistry, \\ University of Missouri-Kansas City \\ School of Dentistry, Kansas City, \\ MO, USA; ${ }^{2}$ Department of Pediatric \\ Dentistry, Children's Mercy Hospital, \\ Kansas City, MO, USA; ${ }^{3}$ Bioengineering \\ Research Center, ${ }^{4}$ Department of \\ Civil, Environmental, and Architectural \\ Engineering, ${ }^{5}$ Department of \\ Mechanical Engineering, University \\ of Kansas, Lawrence, KS, USA; \\ ${ }^{6}$ Department of Restorative Dentistry, \\ State University of Londrina, School \\ of Dentistry, Londrina, Brazil
}

Correspondence: Brenda Bohaty University of Missouri School of Dentistry, 650 East 25th Street. Kansas City, MO 64108, USA

Tel +l 8162352036

$\mathrm{Fax}+18162352157$

Email bohatyb@umkc.edu

\begin{abstract}
Restoring posterior teeth with resin-based composite materials continues to gain popularity among clinicians, and the demand for such aesthetic restorations is increasing. Indeed, the most common aesthetic alternative to dental amalgam is resin composite. Moderate to large posterior composite restorations, however, have higher failure rates, more recurrent caries, and increased frequency of replacement. Investigators across the globe are researching new materials and techniques that will improve the clinical performance, handling characteristics, and mechanical and physical properties of composite resin restorative materials. Despite such attention, large to moderate posterior composite restorations continue to have a clinical lifetime that is approximately one-half that of the dental amalgam. While there are numerous recommendations regarding preparation design, restoration placement, and polymerization technique, current research indicates that restoration longevity depends on several variables that may be difficult for the dentist to control. These variables include the patient's caries risk, tooth position, patient habits, number of restored surfaces, the quality of the tooth-restoration bond, and the ability of the restorative material to produce a sealed tooth-restoration interface. Although clinicians tend to focus on tooth form when evaluating the success and failure of posterior composite restorations, the emphasis must remain on advancing our understanding of the clinical variables that impact the formation of a durable seal at the restoration-tooth interface. This paper presents an update of existing technology and underscores the mechanisms that negatively impact the durability of posterior composite restorations in permanent teeth.
\end{abstract}

Keywords: composites, bonding, dental restorations

\section{Clinical performance of composite versus dental amalgam restorations}

In the United States, 166 million dental restorations were placed in $2005,{ }^{1}$ and clinical studies suggest that more than half were replacements for failed restorations. ${ }^{2}$ It is anticipated that the emphasis on replacement therapy will increase with the phasing out of dental amalgam. Global concerns regarding mercury in the environment are the primary driver for the discontinuation of dental amalgam. Identified as one of the top five mercury-added products, dental amalgam is ranked fifth behind batteries, measuring devices, electrical switches and relays, and mercury-containing light bulbs. ${ }^{3}$

Resin composite is the most common alternative to dental amalgam, ${ }^{4}$ but numerous studies report that composite restorations have more recurrent caries, higher failure rates, and increased frequency of replacement. ${ }^{2,4-10}$ Simecek et al reviewed the dental records of more than 3000 patients and concluded that there was a significantly higher risk of replacement for posterior composite restorations 
as compared to amalgam. ${ }^{4}$ In a study of posterior restorations placed by 243 Norwegian dentists, failed amalgam restorations had a mean age of about 11 years, while the mean age of failed composite restorations was statistically significantly lower at 6 years. ${ }^{8}$ A study of composite and amalgam restorations in the pediatric population indicated that the need for additional treatment was 50\% greater in children receiving composite restorations. ${ }^{11}$ Depending on factors, including the size of the restoration, tooth location, and patient type, the lifetime of large to moderate posterior composite restorations is approximately one-half that of dental amalgam. ${ }^{12}$

The use of composite to restore form and function for posterior teeth damaged by disease, age, or trauma is gaining wide acceptance by the dental community. A myriad of factors can influence the clinical success of class II composite restorations. Clinical parameters, including patient characteristics, tooth preparation, matrix utilization, and composite composition-dentin bonding will be the focus of this review article.

\section{Patient selection}

The popularity and demand for resin-based posterior restorations has been increasing steadily since the introduction of these materials in the mid-1950s. The societal focus on aesthetics as well as the worldwide move toward eliminating amalgam restorative materials has contributed to this phenomenon. ${ }^{3}$ Unfortunately the success and/or failure of resin-based composite restorations is dependent upon variables that may be difficult for the operator to control. For example, restorations placed in patients with high caries risk have restoration failure rates two times those of patients with low caries risk. ${ }^{13}$ These findings have been documented in the adult as well as the pediatric dental patient population. ${ }^{14}$ Clinical data indicate that regardless of which preparation design is adopted or the type of posterior resin-based restoration that is utilized, the practitioner must give careful consideration to the caries status of the patient and adjust recommendations for restorative materials accordingly.

\section{Tooth preparation}

Posterior resin restorations have been indicated for various types of tooth preparations. In particular, resins are utilized to maximize aesthetics and minimize the loss of tooth structure during preparation. Due to the location of the caries and thus the need to restore proximal surfaces in class II restorations, a number of tooth preparation designs have been advocated. The underlying goal of all of these tooth preparation designs is a reduction in the loss of sound tooth structure.

The "tunnel" technique, as reported by Hunt ${ }^{15}$ and Knight, ${ }^{16}$ has been used to remove proximal caries while leaving the marginal ridge intact. Although potentially promising, the lack of long-term clinical studies limits wide adoption of this technique. ${ }^{17}$ The ability to access and restore a proximal carious lesion directly represents the most conservative proximal restorative technique available. ${ }^{17}$ This technique is relatively successful in preserving intact tooth structure (Figures 1 and 2).

The ability to access proximal carious lesions directly is usually limited. Minibox or "slot" preparations for the restoration of proximal lesions in posterior teeth have also been recommended by clinicians and researchers. These preparation designs have been described as minimally invasive and relatively successful with a reported $70 \%$ success rate over an average of 7 years. ${ }^{18}$

The aforementioned tooth preparation designs successfully limit the removal of sound tooth structure and take advantage of appropriate etching techniques in bonding to intact enamel and dentin. However, depending upon the location and extent of the caries, traditional preparation designs, which involve access through the carious marginal ridge and the removal of infected occlusal enamel and dentin, may be required. These more invasive preparations are indicated in this clinical situation (Figure 3 ) and are well documented in the literature. ${ }^{19}$ Whenever possible, conservative structure-sparing preparation techniques should be used. When restoring proximal surfaces with resin-based composite.

Considerable attention has been devoted to the relationship between cavity type, cavity size, number of surfaces restored, and the risk of restoration failure. As the number of restored surfaces increases, the risk of restoration

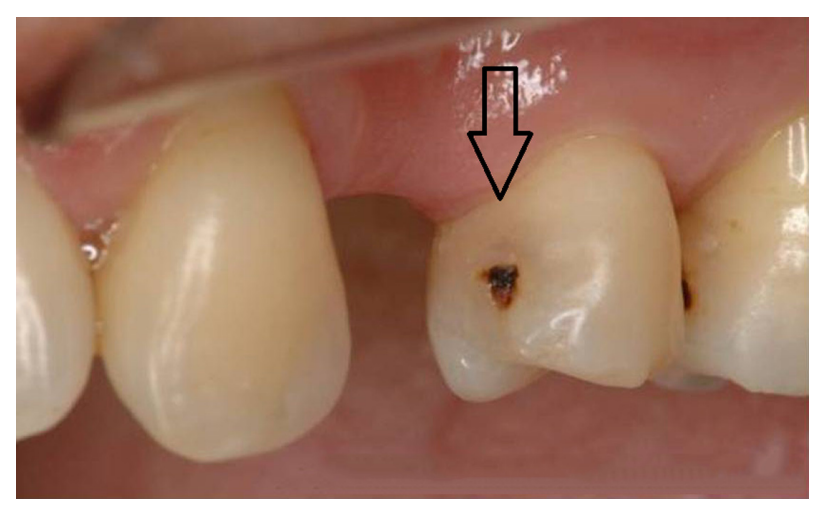

Figure I Proximal carious lesion with direct access. 


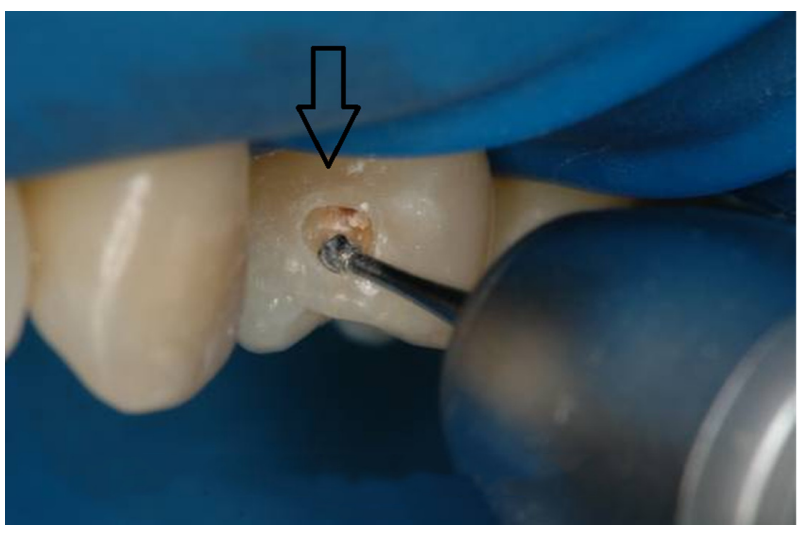

Figure $\mathbf{2}$ Tooth preparation with direct proximal access.

failure also increases. ${ }^{20-22}$ For example, as reported in the 2012 review by Demarco et al,,$^{23}$ single-surface and class I restorations are less likely to fail as compared to multisurface restorations, and class II restorations. To minimize restoration failure and mitigate the effects of bonding multiple tooth surfaces, most clinical strategies have focused on methods to decrease the ratio between the bonded surface area to the nonbonded surface area, also described as the cavity configuration or $\mathrm{C}$-factor. The higher the $\mathrm{C}$-factor the less chance for relaxation of polymerization shrinkage. Some studies have indicated that the increase in $\mathrm{C}$-factor is also associated with decreased bond strength. ${ }^{24,25}$ However, recent investigations have suggested that this finding may not be valid for the newer low-shrink resin-based composites. ${ }^{26}$

Along with preparation design and extent of tissue removal, the position of the tooth in the mouth directly influences the overall clinical performance and longevity of the restoration. Studies suggest that restorations placed in premolars fail less often than similar restorations placed in molars. ${ }^{20,21}$ Intuitively this finding makes sense in that

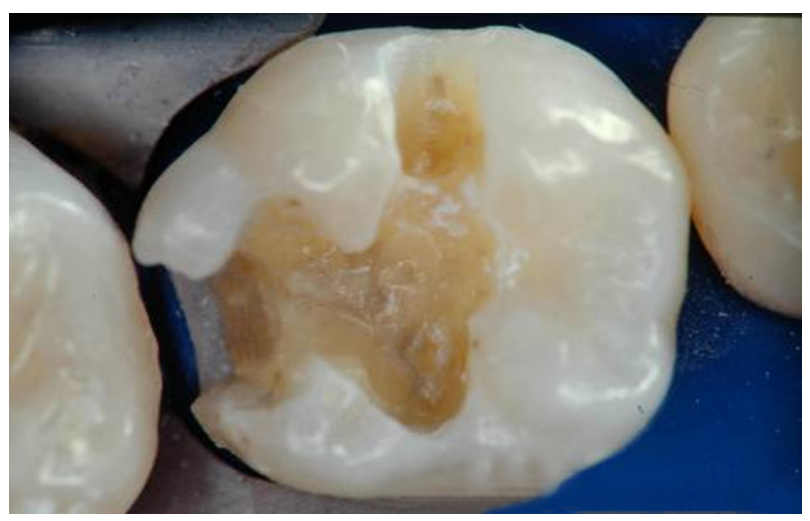

Figure 3 Traditional class II tooth preparation. the masticatory forces and stresses placed on restorations in molar teeth are higher than those placed in premolars. Nonetheless, the findings in terms of tooth position and number of restored surfaces indicate that clinicians should utilize posterior resin composites in areas where aesthetics is deemed essential and should maintain as much tooth structure as possible. Figures 4 and 5 illustrate the aesthetic results obtained when replacing a proximal amalgam restoration with a resin-based composite restoration.

\section{Polymerization and matrices}

The techniques used to fill and cure resin-based composites, particularly in areas of high masticatory stresses, have received considerable attention. The debate among researchers as well as practitioners regarding bulk cure versus incremental cure continues. Incremental filling techniques (Figure 6) have long been recommended due to the polymerization shrinkage associated with dental composites. Reducing the volume of composite that is polymerized at each stage of the restorative procedure minimizes shrinkage and maximizes the conversion of monomers to polymer. This is achieved, in part, by decreasing the attenuation of the curing light. ${ }^{27}$ While incremental filling techniques have been taught and utilized for decades, some studies indicate that incremental filling of resin-based composites produces higher shrinkage stress. ${ }^{27,28}$ In direct contrast, more recent studies report that incremental filling produces lower shrinkage stress when compared to bulk filling techniques. ${ }^{29,30}$ These diverse and contradictory conclusions are likely due to different testing methods. ${ }^{31}$ Currently, manufacturers are striving to produce resin-based composite systems that have

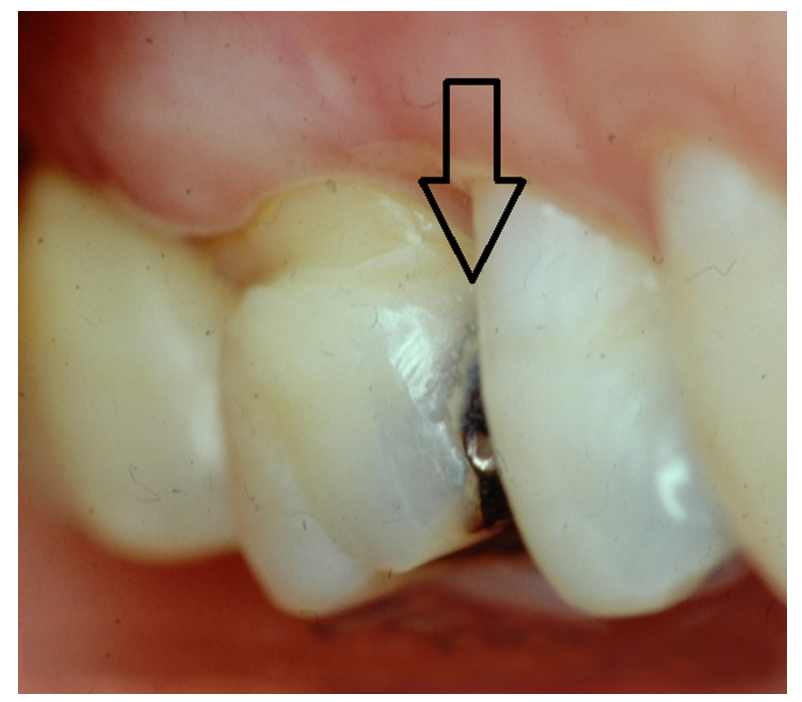

Figure 4 Pre-operative class II amalgam restoration. 


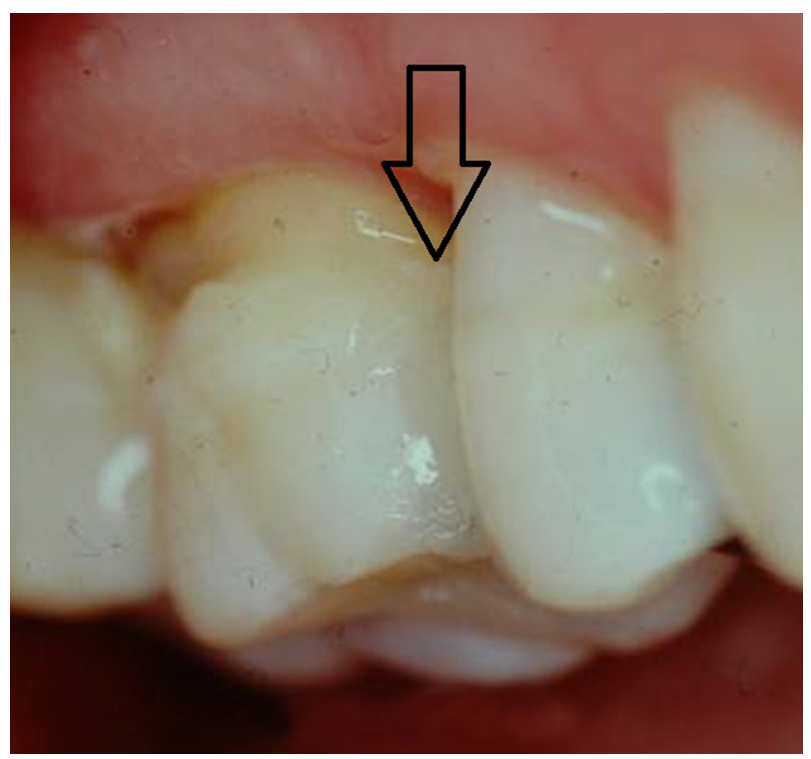

Figure 5 Post-operative class II resin restoration.

less polymerization shrinkage $(<2 \%)$ and, more importantly, reduced polymerization shrinkage stress. Strategies to improve shrinkage include utilizing new low-shrinking monomers or those with an increased molecular weight. ${ }^{26}$ As the low-shrinking composite resins improve, incremental

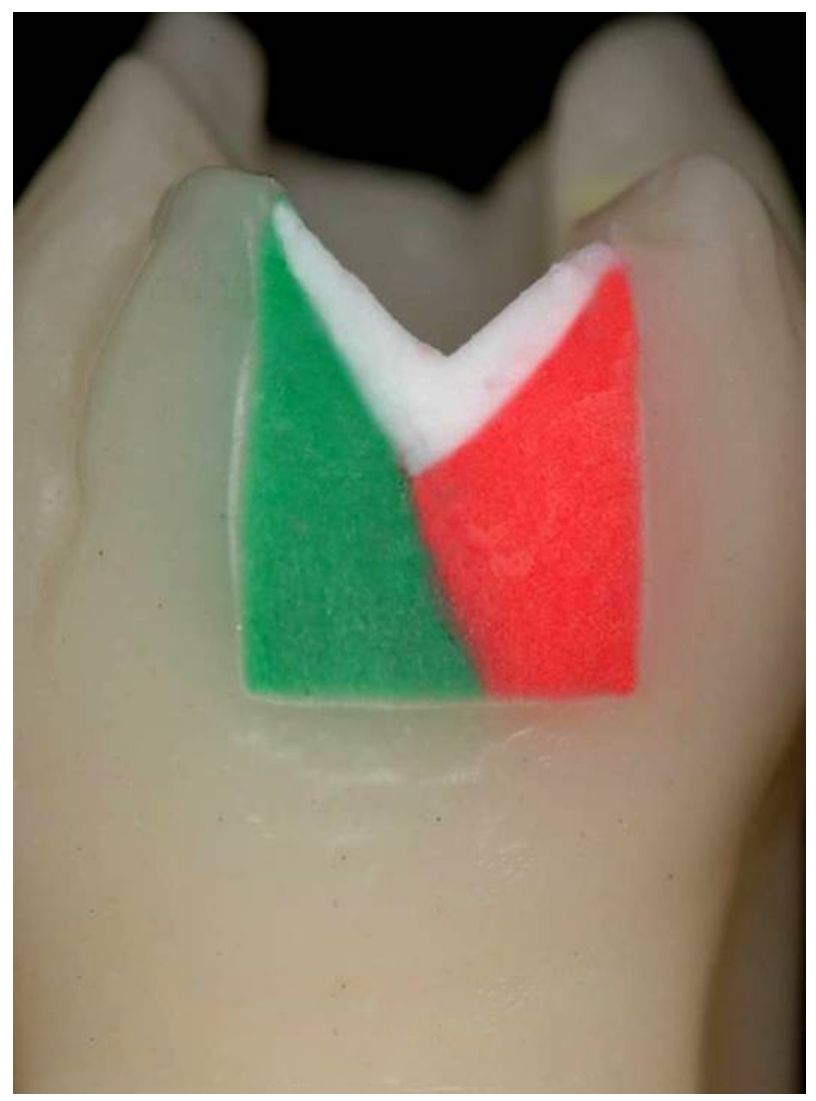

Figure 6 Incremental filling technique representation. filling and curing of posterior composites may no longer be recommended. However, until the long-term clinical success of the lower shrinking composite resin systems is confirmed, using an incremental filling technique in deep cavity preparations is recommended. ${ }^{26}$

The influence of matrix type on the quality of the proximal contact and the ease of placement of class II resin restorations has also been evaluated. The ability to reproduce an appropriate, functional, proximal contact with a class II resin restoration is important to minimize food impaction and thus maintain healthy periodontal tissues. In addition, a poorly adapted and finished proximal restoration may have an "open margin" through which oral fluids, eg, saliva, enzymes, water, and cariogenic bacteria, may penetrate. This marginal leakage can lead to recurrent caries, which is the most often cited reason for composite restoration failure., ${ }^{2,-10}$

Manufacturers have introduced various types of matrices into the dental market with the goal of affecting or influencing the direction of composite shrinkage during polymerization..$^{32}$ The literature no longer supports the concept of "directional polymerization, ${ }^{33}$ but these matrices still exist. Although there are a myriad of different shapes and sizes, the majority of matrices fall into one of two basic types: (1) metal matrices, which are straight or circumferential/precontoured and (2) transparent matrices which are either straight or circumferential/precontoured. Despite the theory that transparent matrices will enhance polymerization at the gingival margin, the recent literature suggests that the choice of matrix does not influence the clinical success of class II posterior resins. ${ }^{32}$

In addition to matrix type, there are numerous tooth separation (wedging) products and techniques. These include wooden wedges and separation rings. The literature suggests that the type of matrix material/wedge does not influence the clinical performance of class II composite restorations. ${ }^{34}$ However, the literature does indicate that no matrix/wedge combination can accurately reproduce an intact proximal surface contact at the precise location of the natural intact tooth. ${ }^{35}$

\section{Composite restoration failures}

Researchers and industry continue their efforts to modify composite resin restorative materials in order to improve their handling characteristics, mechanical and physical properties, and clinical performance. The majority of the current resin composites have mechanical properties that make them suitable for use in all areas of the mouth. The functionality of these restorations, however, in areas of high masticatory 
stress is still a concern. Resin restorations that are placed in areas of high function are more prone to exhibit excessive wear and/or marginal fracture despite the advances in the current materials. Clinicians must exercise caution when placing large resin-based composite restorations in areas of high function. The longevity of posterior resin restorations placed in patients who have a history of clenching or grinding may be particularly limited. ${ }^{35}$

While resin composition, tooth preparation design, and matrix systems may influence the lifetime of posterior composite restorations, the primary factor in the clinical failure of moderate to large composite restorations is secondary caries at the margins of the restorations. ${ }^{8}$ As an example, in a study of radiographs from 459 adults, age 18-19 years, the investigators reported that, among interproximal restorations, the failure rate as a result of secondary or recurrent caries was $43 \%$ for composite as compared to $8 \%$ for amalgam. ${ }^{7}$ In a separate study of amalgam and composite restorations placed in 8-12-year-old children, the primary reason for failure of both materials was secondary caries, but secondary caries was 3.5 times higher in composite restorations. ${ }^{5}$

An increase in secondary caries at the margins of composite restorations suggests that the seal at the composite-tooth interface is not adequate to resist the physical, chemical, and mechanical stresses that are present in the mouth. The failure of moderate to large composite restorations has been linked to the degradation of the bond at the tooth surface-composite material interface ${ }^{12,36-41}$ and an increase in the concentration of the cariogenic bacterium Streptococcus mutans at the perimeter of these materials. ${ }^{42-46}$ Degradation of the bond at the interface between the tooth and composite has been associated with the failure of adhesives to form an impervious seal with the dentin., ${ }^{2,41-50}$ Failure of the adhesive/dentin ( $\mathrm{a} / \mathrm{d}$ ) bond leads to open pores at the composite-tooth interface and bacterial enzymes, oral fluids, and even bacteria can penetrate these open pores. ${ }^{51}$ Data from in vivo and in vitro studies indicate that the infiltration of these agents into the voids between the tooth and composite will lead to recurrent caries, hypersensitivity, and pulpal inflammation. ${ }^{41,47,52,53}$ Results from clinical studies indicate loss of retention, poor marginal adaptation, and marginal discoloration when the a/d interface is exposed to the oral cavity. ${ }^{54}$ Effective mechanical bonding between the composite restoration and treated enamel has been achieved using appropriate acid-etching protocols, but failure of the bond at the a/d interface threatens the long-term clinical survival of moderate to large posterior composite restorations..$^{39,41,43,52,55-57}$
Bonding failures have been commonly tracked to the gingival margin of class II composite restorations. ${ }^{58} \mathrm{~A}$ separation between the composite material and tooth surface has been noted at the gingival margin. ${ }^{55}$ In class II composite restorations, there is generally little enamel available for bonding at the gingival margin; therefore, the bond at this site depends on the integrity of the seal formed with dentin. Gaps at the gingival margin have been attributed to unreliable dentin bonding. ${ }^{55,57}$ In a study comparing the microtensile $\mathrm{a} / \mathrm{d}$ bond strength of gingival and proximal walls of class II composite restorations, the adhesive bond to the gingival wall was significantly weaker. ${ }^{59}$ A complementary spectroscopic study reported a twofold difference in the extent of dentin demineralization at the proximal and gingival margins. ${ }^{50}$ The difference in demineralization suggests less mineralized dentin at the gingival margin. The cumulative effect of less mineral, increased density, and size of the tubules ${ }^{60}$ would mean faster and deeper etching at the gingival margin as compared to the proximal wall. Although the etch was deeper at the gingival margin, there was considerably less adhesive infiltration of the demineralized dentin matrix at the gingival margin. ${ }^{50}$ The discrepancy between etching depth and adhesive infiltration led to a large area of exposed collagen at the gingival margin.

Yoshiyama et al suggested that the increased number of tubules per unit area at the gingival margin would promote efficient adhesive infiltration at this margin.${ }^{61}$ However, other variables, including water content, interfere with efficient adhesive infiltration at the gingival margin. Water content is higher in dentin at the gingival margin as compared to the proximal wall. Water content is increased because of the water present within the demineralized dentin matrix and patent tubules that contain a great deal of dentinal fluid. The presence of this fluid contributes to the contamination of the prepared surface. ${ }^{62}$ The increased water leads to reduced adhesive infiltration and lower monomer/polymer conversion of the adhesive at the gingival margin as compared to the proximal wall. ${ }^{50}$ The impact of water upon the effectiveness of bonding is further supported by in vitro investigations that indicate that adhesive monomers or oligomers and unprotected collagen at the gingival margin of class II composite restorations undergo hydrolytic degradation after 90 days of aqueous storage. ${ }^{49}$

Wet bonding techniques were introduced in the early 1990 s to counteract the problems noted with collagen collapse following drying of the demineralized dentin matrix. ${ }^{63-66}$ Wet bonding means that the demineralized dentin matrix is fully hydrated throughout the bonding protocol. Using this 
procedure, the channels between the demineralized dentin collagen fibrils are filled with water, solvent, conditioner, and/or oral fluids. ${ }^{67,68}$ Adhesive must diffuse into the fluidfilled spaces of the substrate and along the collagen fibrils. Ideally, the solvent in combination with hydrophilic monomers, eg, hydroxyethyl methacrylate (HEMA) conditions the collagen to remain expanded during adhesive infiltration. However, HEMA, a primary component in many singlebottle, commercial, dentin adhesives, can dramatically reduce the evaporation of water. ${ }^{69}$ Hydrophobic monomers, such as 2,2-bis[4(2-hydroxy-3-methacryloyloxy-propyloxy)-phenyl] propane (BisGMA), would resist diffusing into these sites where there is residual water. ${ }^{70-72}$

In the in vivo situation, there may be little control over the amount of water left on the tooth. Thus, it is possible to leave the dentin surface so wet that the adhesive physically separates into hydrophobic- and hydrophilic-rich phases. ${ }^{71,73,74}$ Indeed, results from laboratory investigations indicate that excess moisture prohibited the formation of an impervious structurally integrated a/d bond at the gingival margin of class II composite restorations. ${ }^{49,50}$

Under clinical conditions, dentists must routinely attempt to bond to naturally wet substrates, eg, caries-affected dentin ${ }^{75}$ or deep dentin. ${ }^{76-79}$ The water content of caries-affected dentin is 2.7 times greater than that of normal dentin. ${ }^{75}$ Exposed tubules account for $22 \%$ of the surface area in deep dentin. In contrast, exposed tubules account for $1 \%$ of the surface area of dentin close to the dentino-enamel junction. ${ }^{80}$ The large increase in exposed tubules in deep dentin means that pulpal fluid will contribute additional moisture to that already present within the demineralized dentin matrix. With the sensitivity of our current adhesives to excess moisture, it is obvious that bonding to these clinically relevant substrates is a formidable challenge. ${ }^{79,81-83}$ This difficulty highlights the potential limitations in utilizing resin-based composites to restore large, deep, carious lesions.

\section{Sensitivity of adhesive to wet bonding conditions}

Water blisters that form in adhesives placed on overly wet surfaces ${ }^{84-86}$ and adhesive phase separation that leads to very limited infiltration of the critical but hydrophobic dimethacrylate component ${ }^{71,87,88}$ are two examples of the sensitivity of our current adhesives to excess moisture. The optimum amount of wetness varies as a function of the adhesive system. ${ }^{89}$ It is impossible to simultaneously achieve uniform wetness on all of the walls of the cavity preparation..$^{90}$ In short, wet bonding is a very technique-sensitive procedure. Optimum bonding with our current commercial dentin adhesives occurs over a very narrow range of conditions, eg, water content. ${ }^{78}$

Strategies to promote bonding of the resinous materials to intrinsically wet dentin substrates include the incorporation of ionic and hydrophilic monomers into the adhesive. ${ }^{91}$

These adhesives etch and prime simultaneously, thus addressing the problems of collagen collapse and simplifying the bonding protocol. The hydrophilicity of these adhesives enhances water sorption, which can lead to hydrolytic breakdown in the mouth. ${ }^{85,90,92}$ With these systems, the bonded interface lacks a nonsolvated hydrophobic resin coating. The hybrid layers made with these adhesive systems behave as semi-permeable membranes; water is transferred throughout the bonded interface even after adhesive polymerization. ${ }^{54}$ The increase in the concentration of hydrophilic monomers in these systems has been associated with decreased structural integrity at the $\mathrm{a} / \mathrm{d}$ interface. ${ }^{54,93}$ Deterioration of the $\mathrm{a} / \mathrm{d}$ bond formed with these systems was noted after 1 year of in vivo aging. ${ }^{94}$ These results suggest that hydrophilicity and hydrolytic stability of resin monomers are generally antagonistic. ${ }^{90}$

\section{Effects of function, fatigue, and degradation}

When measured immediately, dentin-composite bonds are generally considered adequate to tolerate conditions in the mouth, but these bonds deteriorate with time. The two major mechanisms of deterioration are fatigue and hydrolysis. ${ }^{95}$ Fatigue has been linked to stresses transmitted to the bond by occlusal forces, thermal expansion and contraction, and polymerization shrinkage of the composite. Chronic deterioration of the dentin-composite bond is also related to hydrolysis and leaching of the adhesive that has infiltrated the tooth structure..$^{70,79}$

Fatigue investigations have indicated that the overall time-dependent behavior of the composite-tooth interface is a complex function of the individual material phases. For example, microfinite element analyses have shown that each material phase at the a/d interface experiences different stress concentrations at functional loads. ${ }^{96,97}$ The overall failure behavior of the bond at the a/d interface is not determined by the weakest component but by the component whose stress concentration is closest to its failure strength. Similarly, the overall fatigue life of the a/d interface is governed by the material component with the shortest fatigue life under a given loading condition. ${ }^{98}$

Under masticatory function the material components at the composite-tooth interface are subjected to both chemical and mechanical stresses. The interplay between these 
stresses can result in a deterioration of the properties of the material over time. The breaking of covalent bonds by addition of water to ester bonds is considered one of the primary reasons for deterioration of the adhesive at the interface between the composite and tooth. ${ }^{89,90}$ Interestingly, degradation of methacrylate ester groups produces carboxylic acids - the same functional group that is the culprit in lactic acid-induced dental caries. The change in mechanical properties of the materials can be contributed to a variety of mechanisms that include proliferation of surface and subsurface flaws. ${ }^{95,97,99-101}$ These flaws in combination with the chemical and biochemical stresses that are present in the mouth can then lead to restoration failure.

In conclusion, the $\mathrm{a} / \mathrm{d}$ bond can be the first defense against substances that may penetrate and ultimately undermine the gingival margin in composite restorations in vivo. It has been hypothesized that the in vivo degradation of the bond at the $\mathrm{a} / \mathrm{d}$ interface follows a cascade of events that begins when the dentin is acid etched ${ }^{102,103}$ Disruption of the tooth structure by acid etching exposes and activates proteolytic enzymes, eg, matrix metalloproteinases (MMPs), that can degrade the exposed collagen component of the hybrid layer. ${ }^{104,105}$ The following factors inhibit the formation of a durable $\mathrm{a} / \mathrm{d}$ bond: (1) water sorption and hydrolysis of the adhesive resin; (2) inadequate monomer/polymer conversion of the infiltrating adhesive; (3) incomplete resin infiltration of the demineralized dentin matrix; (4) incomplete solvent evaporation; and (5) enzymatic challenges within the cavity preparation through exposure to oral fluids. ${ }^{49,71,83,104-115}$ Although durable $\mathrm{a} / \mathrm{d}$ bonds are critical for maintaining a seal at the toothcomposite interface, the properties of the materials are only one part of an extremely complex problem. ${ }^{116}$

\section{Summary}

Restoring posterior teeth with resin-based composite materials continues to gain popularity among clinicians, and the demand for such aesthetic restorations is increasing. Manufacturers are working aggressively to improve resin composite materials by modifying components to decrease polymerization shrinkage, to improve mechanical and physical properties, and to enhance handling characteristics. The two main causes of posterior composite restoration failure are secondary caries and fracture (restoration or tooth). ${ }^{35}$ A review and update of posterior resin composites in terms of preparation design, matrix choice, and resin systems demonstrate the limited extent to which these factors influence the overall clinical lifetime of resins placed in posterior teeth. Clinical and patient factors, including caries risk, cavity size, cavity type, number of restored surfaces, and position of the tooth in the mouth must be given careful attention in the selection of any restorative material including composite resins.

While clinicians tend to focus on tooth form and function when evaluating the success and failure of posterior resins, the emphasis must remain in advancing our understanding and knowledge of the intricate and complicated characteristics of the restoration-tooth interface. This paper presents an update in existing technology and underscores the mechanisms that negatively impact the durability of posterior composites in permanent teeth.

\section{Acknowledgments}

The authors gratefully acknowledge partial support for this work by the National Institute of Health and the National Institute of Dental and Craniofacial Research (R01DE014392 and R01 DE022054).

\section{Disclosure}

The authors report no conflicts of interest in this work.

\section{References}

1. Beazoglou T, Eklund S, Heffley D, Meiers J, Brown LJ, Bailit H. Economic impact of regulating the use of amalgam restorations. Public Health Rep. 2007;122(5):657-663.

2. Murray PE, Windsor LJ, Smyth TW, Hafez AA, Cox CF. Analysis of pulpal reactions to restorative procedures, materials, pulp capping, and future therapies. Crit Rev Oral Biol Med. 2002;13(6):509-520.

3. Palmer C. Good progress reported in mercury treaty talks. ADA News. 2011;42(21):1-2.

4. Simecek JW, Diefenderfer KE, Cohen ME. An evaluation of replacement rates for posterior resin-based composite and amalgam restorations in US. Navy and marine corps recruits. J Am Dent Assoc. 2009;140(2): 200-209.

5. Bernardo M, Luis H, Martin MD, et al. Survival and reasons for failure of amalgam versus composite posterior restorations placed in a randomized clinical trial. J Am Dent Assoc. 2007;138(6):775-783.

6. Malhotra N, Mala K, Acharya S. Resin-based composite as a direct esthetic restorative material. Compend Contin Educ Dent. 2011;32(5): 14-23.

7. Levin L, Coval M, Geiger SB. Cross-sectional radiographic survey of amalgam and resin-based composite posterior restorations. Quintessence Int. 2007;38(6):511-514.

8. Mjor IA, Dahl JE, Moorhead JE. Age of restorations at replacement in permanent teeth in general dental practice. Acta Odontol Scand. 2000;58(3):97-101.

9. Opdam NJ, Bronkhorst EM, Loomans BA, Huysmans MC. 12-year survival of composite vs amalgam restorations. J Dent Res. 2010;89(10): 1063-1067.

10. Soncini JA, Maserejian NN, Trachtenberg F, Tavares M, Hayes C. The longevity of amalgam versus compomer/composite restorations in posterior primary and permanent teeth: findings From the New England Children's Amalgam Trial. J Am Dent Assoc. 2007;138(6): 763-772.

11. DeRouen TA, Martin MD, Leroux BG, et al. Neurobehavioral effects of dental amalgam in children: a randomized clinical trial. JAMA. 2006;295(15):1784-1792. 
12. Van Nieuwenhuysen JP, D'Hoore W, Carvalho J, Qvist V. Long-term evaluation of extensive restorations in permanent teeth. J Dent. 2003; 31(6):395-405.

13. Kohler B, Rasmusson CG, Odman P. A five-year clinical evaluation of Class II composite resin restorations. J Dent. 2000;28(2):111-116.

14. Trachtenberg F, Maserejian NN, Tavares M, Soncini JA, Hayes C. Extent of tooth decay in the mouth and increased need for replacement of dental restorations: the New England Children's Amalgam Trial. Pediatr Dent. 2008;30(5):388-392.

15. Hunt PR. A modified class II cavity preparation for glass ionomer restorative materials. Quintessence Int Dent Dig. 1984;15(10): 1011-1018.

16. Knight GM. The tunnel restoration - nine years of clinical experience using capsulated glass ionomer cements. Case report. Aust Dent J. 1992;37(4):245-251.

17. Wiegand A, Attin T. Treatment of proximal caries lesions by tunnel restorations. Dent Mater. 2007;23(12):1461-1467.

18. Tyas MJ, Anusavice KJ, Frencken JE, Mount GJ. Minimal intervention dentistry - a review. FDI Commission Project 1-97. Int Dent J. 2000; 50(1):1-12.

19. Lopes GC, Vieira LC, Araujo E. Direct composite resin restorations: a review of some clinical procedures to achieve predictable results in posterior teeth. J Esthet Restor Dent. 2004;16(1):19-31.

20. Da Rosa Rodolpho PA, Donassollo TA, Cenci MS, et al. 22-Year clinical evaluation of the performance of two posterior composites with different filler characteristics. Dent Mater. 2011;27(10):955-963.

21. Da Rosa Rodolpho PA, Cenci MS, Donassollo TA, Loguercio AD, Demarco FF. A clinical evaluation of posterior composite restorations: 17-year findings. J Dent. 2006;34(7):427-435.

22. Plasmans PJ, Creugers NH, Mulder J. Long-term survival of extensive amalgam restorations. J Dent Res. 1998;77(3):453-460.

23. Demarco FF, Correa MB, Cenci MS, Moraes RR, Opdam NJ. Longevity of posterior composite restorations: not only a matter of materials. Dent Mater. 2012;28(1):87-101.

24. El-Sahn NA, El-Kassas DW, El-Damanhoury HM, Fahmy OM, Gomaa H, Platt JA. Effect of C-factor on microtensile bond strengths of low-shrinkage composites. Oper Dent. 2011;36(3):281-292.

25. Shirai K, De Munck J, Yoshida Y, et al. Effect of cavity configuration and aging on the bonding effectiveness of six adhesives to dentin. Dent Mater. 2005;21(2):110-124.

26. Van Ende A, Mine A, De Munck J, Poitevin A, Van Meerbeek B. Bonding of low-shrinking composites in high C-factor cavities. J Dent. 2012;40(4):295-303.

27. Kuijs RH, Fennis WM, Kreulen CM, Barink M, Verdonschot N. Does layering minimize shrinkage stresses in composite restorations? J Dent Res. 2003;82(12):967-971.

28. Abbas G, Fleming GJ, Harrington E, Shortall AC, Burke FJ. Cuspal movement and microleakage in premolar teeth restored with a packable composite cured in bulk or in increments. J Dent. 2003;31(6): $437-444$.

29. Lee MR, Cho BH, Son HH, Um CM, Lee IB. Influence of cavity dimension and restoration methods on the cusp deflection of premolars in composite restoration. Dent Mater. 2007;23(3):288-295.

30. Park J, Chang J, Ferracane J, Lee IB. How should composite be layered to reduce shrinkage stress: incremental or bulk filling? Dent Mater. 2008;24(11):1501-1505.

31. Kwon Y, Ferracane J, Lee IB. Effect of layering methods, composite type, and flowable liner on the polymerization shrinkage stress of light cured composites. Dent Mater. 2012;28(7):801-809.

32. Cenci MS, Demarco FF, Pereira CL, Lund RG, de Carvalho RM. One-year comparison of metallic and translucent matrices in Class II composite resin restorations. Am J Dent. 2007;20(1):41-45.

33. Versluis A, Tantbirojn D, Douglas WH. Do dental composites always shrink toward the light? J Dent Res. 1998;77(6):1435-1445.

34. Cenci MS, Lund RG, Pereira CL, de Carvalho RM, Demarco FF. In vivo and in vitro evaluation of Class II composite resin restorations with different matrix systems. J Adhes Dent. 2006;8(2):127-132.
35. Kampouropoulos D, Paximada C, Loukidis M, Kakaboura A. The influence of matrix type on the proximal contact in Class II resin composite restorations. Oper Dent J. 2010;35(4):454-462.

36. Collins CJ, BR, Hodge KLV. A clinical evaluation of posterior composite resin restorations: 8-year findings. J Dent. 1998;26:311-317.

37. Mair LH. Ten-year clinical assessment of three posterior resin composites and two amalgams. Quintessence Int. 1998;29(8):483-490.

38. Mjor IA, Dahl JE, Moorhead JE. Placement and replacement of restorations in primary teeth. Acta Odontologica Scandinavica. 2002;60:25-28.

39. Nordbo H, LJ, von der Fehr FR. Saucer-shaped cavity preparations for posterior aproximal resin composite restorations: Observations up to 10 years. Quintessence Int. 1988;29(1):5-11.

40. Owens BM, Johnson WW. Effect of insertion technique and adhesive system on microleakage of Class $\mathrm{V}$ resin composite restorations. J Adhes Dent. 2005;7:303-308.

41. Van Meerbeek B, Van Landuyt K, De Munck J, et al. Techniquesensitivity of contemporary adhesives. Dent Mater J. 2005;24(1): $1-13$.

42. Anusavice KJ. Management of dental caries as a chronic infectious disease. J Dent Educ. 1998;62:791-802.

43. Dunne SM, Gainsford ID, Wilson NHF. Current materials and techniques for direct restorations in posterior teeth. Part 1: silver amalgam. Int Dent J. 1997;47:123-136.

44. Hansel C, Leyhausen G, Mai UE, Geurtsen W. Effects of various resin composite (co)monomers and extracts on two caries-associated microorganisms in vitro. J Dent Res. 1998;77:60-67.

45. Santerre JP, Shajii L, Leung BW. Relation of dental composite formulations to their degradation and the release of hydrolyzed polymericresin-derived products. Crit Rev Oral Biol Med. 2001;12:136-151.

46. Svanberg M, Mjor IA, Orstavik D. Mutans Streptococci in plaque from margins of Amalgam composite, and glass-ionomer restorations. J Dent Res. 1990;69(3):861-864.

47. Hashimoto M, Ohno H, Kaga M, Endo K, Sano H, Oguchi H. Resin-tooth adhesive interfaces after long-term function. Am J Dent. 2001;14(4):211-215.

48. Meiers JC, Kresin J. Cavity disinfectants and dentin bonding. Oper Dent. 1996;21:153-159.

49. Spencer P, Wang Y, Bohaty B. Interfacial chemistry of moisture-aged class II composite restorations. J Biomed Mater Res B Appl Biomater. 2006;77(2):234-240.

50. Wang Y, Spencer P. Interfacial chemistry of class II composite restoration: structure analysis. J Biomed Mater Res A. 2005;75(3): 580-587.

51. Gallo LM, Nickel JC, Iwasaki LR, Palla S. Stress-field translation in the healthy human temporomandibular joint. J Dent Res. 2000;79(10): 1740-1746.

52. Andersson-Wenckert IE, van Dijken JW, Kieri C. Durability of extensive class II open-sandwich restorations with a resin-modified glass ionomer cement after 6 years. Am J Dent. 2004;17:43-50.

53. Brannstrom M. Communication between the oral cavity and the dental pulp associated with restorative treatment. Oper Dent. 1984;9:57-68.

54. Breschi L, Mazzoni A, Ruggeri A, Cadenaro M, Di Lenarda R, De Stefano Dorigo E. Dental adhesion review: aging and stability of the bonded interface. Dent Mater. 2008;24(1):90-101.

55. Roulet JF. Benefits and disadvantages of tooth-coloured alternatives to amalgam. J Dent. 1997;25:459-473.

56. Van Dijken JW. Direct resin composite inlays/onlays: an 11 year follow-up. J Dent. 2000;28:299-306.

57. Kleverlaan CJ, Feilzer AJ. Polymerization shrinkage and contraction stress of dental resin composites. Dent Mater. 2005;21:1150-1157.

58. Bouillaguet S, Ciucchi B, Jacoby T, Wataha JC, Pashley D. Bonding characteristics to dentin walls of class II cavities, in vitro. Dent Mater. 2001;17:316-321.

59. Purk JH, Dusevich V, Glaros AG, Spencer P, Eick JD. In vivo versus in vitro microtensile bond strength of axial versus gingival cavity preparation walls in class II resin-based composite restorations. J Am Dent Assoc. 2004;135:185-193. 
60. Garberoglio P. The ratio of the densities of dentinal tubules on the cervical and axial wall in cavities. Quintessence Int. 1994;25: 49-52.

61. Yoshiyama M, Carvalho R, Sano H, Horner J, Brewer PD, Pashley DH. Interfacial morphology and strength of bonds made to superficial versus deep dentin. Am J Dent. 1995;8:297-302.

62. Pashley DH. Clinical correlations of dentin structure and function. J Prosthet Dent. 1991;66:777-781.

63. Gwinnett AJ. Chemically conditioned dentin: a comparison of conventional and environmental scanning electron microscopy findings. Dent Mater. 1994;10:150-155.

64. Gwinnett AJ. Dentin bond strength after air drying and rewetting. Am J Dent. 1994;7:144-148.

65. Gwinnett AJ. Altered tissue contribution to interfacial bond strength with acid conditioned dentin. Am J Dent. 1994;7:243-246.

66. Kanca J. Improved bond strength through acid etching of dentin and bonding to wet dentin surfaces. J Am Dent Assoc. 1992;123:235-243.

67. Pashley DH, Ciucchi B, Sano H, Horner JA. Permeability of dentin to adhesive agents. Quintessence Int. 1993;24:618-631.

68. Nakabayashi N, Watanabe A, Arao T. A tensile test to facilitate identification of defects in resin-bonded dentin specimens. J Dent. 1998;26:379-385.

69. Pashley EL, Zhang Y, Lockwood PE, Rueggeberg FA, Pashley DH. Effects of HEMA on water evaporation from water-HEMA mixtures. Dent Mater. 1998;14(1):6-10.

70. Wang Y, Spencer P. Hybridization efficiency of the adhesive dentin interface with wet bonding. J Dent Res. 2003;82:141-145.

71. Spencer $P$, Wang Y. Adhesive phase separation at the dentin interface under wet Bonding conditions. J Biomed Mater Res. 2002;62(3):447-456.

72. Spencer P, Wang Y, Walker MP, Wieliczka DM, Swafford JR Interfacial chemistry of the dentin/adhesive bond. J Dent Res. 2000; 79(7):1458-1463.

73. Ye Q, Park J, Laurence JS, Parthasarathy R, Misra A, Spencer P. Ternary phase diagram of model dentin adhesive exposed to over-wet environments. J Dent Res. 2011;90(12):1434-1438.

74. Ye Q, Park JG, Parthasarathy R, et al. Quantitative analysis of aqueous phase composition of model dentin adhesives experiencing phase separation. J Biomed Mater Res Part B: Appl Biomaterials. 2012;100B:1086-1092.

75. Ito S, Hashimoto M, Wadgaonkar B, et al. Effects of resin hydrophilicity on water sorption and changes in modulus of elasticity. Biomaterials. 2005;26(33):6449-6459.

76. Marshall GW, Marshall SJ, Kinney JH, Balooch M. The dentin substrate:structure and properties related to bonding. J Dent. 1997;25: 441-458.

77. Pereira PNR, Okuda M, Sano H, Yoshikawa T, Burrow MF, Tagami J. Effect of intrinsic wetness and regional difference on dentin bond strength. Dent Mater. 1999;15:46-53.

78. Roulet JF, Degrange M, editors. Adhesion: The Silent Revolution in Dentistry, 1st ed: Quintessence Publishing Co, Inc; Berlin, Germany; 1999:263.

79. Wang Y, Spencer P, Hager C, Bohaty B. Comparison of interfacial characteristics of adhesive bonding to superficial versus deep dentin using SEM and staining techniques. J Dent. 2006;34:26-34.

80. Pashley DH. Dentin: A dynamic substrate in dentistry. Scanning Microsc. 1989;3:161-176.

81. Spencer P, Wang Y, Katz JL, Misra A. Physicochemical interactions at the dentin/adhesive interface using FTIR chemical imaging. J Biomed Opt. 2005;10(3):031104.

82. Wang Y, Spencer P. Continuing etching of an all-in-one adhesive in wet dentin tubules. $J$ Dent Res. 2005;84:350-354.

83. Wang Y, Spencer P, Yao X, Brenda B. Effect of solvent content on resin hybridization in wet dentin bonding. J Biomed Mater Res A. 2007;82(4): 975-983.

84. Tay FR, Gwinnett AJ, Pang KM, Wei SHY. An optical, micromorphological study of surface moisture in the total etched resin-dentin interface. Am J Dent. 1996;9:43-48.
85. Tay FR, Gwinnett AJ, Wei SHY. The overwet phenomenon: a transmission electron microscopic study of surface moisture in the acidconditioned, resin-dentin interface. Am J Dent. 1996;9:161-166.

86. Tay FR, Gwinnett AJ, Wei SHY. Micromophological spectrum from overdrying to overwetting acid-conditioned dentin in water-free, acetonebased, single-bottle primer/adhesives. Dent Mater. 1996;12:236-244.

87. Gwinnett AJ, Tay FR, Pang KM, Wei SHY. Quantitative Contribution of the Collagen Network in Dentin Hybridization. Am J Dent. 1996;9: $140-144$.

88. Wang Y, Spencer P, Yao X. Micro-raman imaging analysis of monomer/ mineral distribution in intertubular region of adhesive/dentin interfaces. J Biomed Optics. 2006;11:024005-1-024005-7.

89. Tay FR, Pashley DH. Water treeing - a potential mechanism for degradation of dentin adhesives. Am J Dent. 2003;16(1):6-12.

90. Tay FR, Pashley DH. Have dentin adhesives become too hydrophilic? J Can Dent Assoc. 2003;69(11):726-731.

91. Hebling J, Pashley DH, Tjaderhane L, Tay FR. Chlorhexidine arrests subclinical degradation of dentin hydbrid layers in vivo. J Dent Res. 2005;84(8):741-746.

92. Parthasarathy R, Misra A, Park J, Ye Q, Spencer P. Diffusion coefficients of water and leachables in methacrylate-based crosslinked polymers using absorption experiments. J Mater Sci Mater Med. 2012;23(5):1157-1172.

93. Peumans M, Kanumilli P, De Munck J, Van Landuyt K, Lambrechts P, Van Meerbeek B. Clinical effectiveness of contemporary adhesives: a systematic review of current clinical trials. Dent Mater. 2005;21(9):864-881.

94. Donmez N, Belli S, Pashley DH, Tay FR. Ultrastructural correlates of in vivo/in vitro bond degradation in self-etch adhesives. J Dent Res. 2005;84(4):355-359.

95. Staninec M, Kim P, Marshall GW, Ritchie RO, Marshall SJ. Fatigue of dentin-composite interfaces with four-point bend. Dent Mater. 2008;24(6):799-803.

96. Misra A, Spencer P, Marangos O, Wang Y, Katz JL. Micromechanical analysis of dentin/adhesive interface by the finite element method. J Biomed Mater Res B Appl Biomater. 2004;70(1):56-65.

97. Misra A, Spencer P, Marangos O, Wang Y, Katz JL. Parametric study of the effect of phase anisotropy on the micromechanical behaviour of dentin-adhesive interfaces. J R Soc Interface. 2005;2(3):145-157.

98. Singh V, Misra A, Marangos O, et al. Fatigue life prediction of dentinadhesive interface using micromechanical stress analysis. Dent Mater. 2011;27(9):e187-e195.

99. Katz JL, Misra A, Spencer P, et al. Multiscale mechanics of hierarchical structure/property relationships in calcified tissues and tissue/material interfaces. Mater Sci Eng A Struct Mater. 2007;27(3):450-468.

100. Singh V, Misra A, Marangos O, et al. Viscoelastic and fatigue properties of model methacrylate-based dentin adhesives. J Biomed Mater Res B Appl Biomater. 2010;95(2):283-290.

101. Belli R, Baratieri LN, Braem M, Petschelt A, Lohbauer U. Tensile and bending fatigue of the adhesive interface to dentin. Dent Mater. 2010;26(12):1157-1165.

102. Pashley DH, Tay FR, Yiu C, et al. Collagen degradation by hostderived enzymes during aging. J Dent Res. 2004;83(3):216-221.

103. Sano H. Microtensile testing, nanoleakage, and biodegradation of resin-dentin bonds. J Dent Res. 2006;85(1):11-14.

104. Mazzoni A, Pashley DH, Nishitani Y, et al. Reactivation of quenched endogenous proteolytic activities in phosphoric acid-etched dentine by etch-and-rinse adhesives. Biomaterials. 2006;27(25): 4470-4476.

105. Tay FR, Pashley DH, Loushine RJ, Weller RN, Monticelli F, Osorio R. Self-etching adhesives increase collagenolytic activity in radicular dentin. J Endodo. 2006;32(9):862-868.

106. Spencer P, Swafford JR. Unprotected protein at the dentin-adhesive interface. Quintessence Int. 1999;30(7):501-507.

107. Spencer P, Ye Q, Park J, Topp EM, et al. Adhesive/dentin interface: the weak link in the composite restoration. Ann Biomed Eng. 2010;38(6): 1989-2003. 
108. Ye Q, Spencer P, Wang Y, Misra A. Relationship of solvent to the photopolymerization process, properties and structure in model dentin adhesives. J Biomed Mater Res A. 2007;80(2):342-350.

109. Guo X, Spencer P, Wang Y, Ye Q, Yao X, Williams K. Effects of a solubility enhancer on penetration of hydrophobic component in model adhesives into wet demineralized dentin. Dent Mater. 2007;23: 1473-1481.

110. Kostoryz EL, Dharmala K, Ye Q, et al. Enzymatic biodegradation of HEMA/BisGMA adhesives formulated with different water content. J Biomed Mater Res B: Appl Biomater. 2009;88B:394-401.

111. Guo X, Wang Y, Spencer P, Ye Q, Yao X. Effects of water content and initiator composition on photopolymerization of a model BisGMA/ HEMA resin. Dent Mater. 2008;24(6):824-831.

112. Ye Q, Wang Y, Spencer P. Nanophase separation of polymers exposed to simulated bonding conditions. J Biomed Mater Res B: Appl Biomater. 2009;88B:339-348.
113. Park JG, Ye Q, Topp EM, Spencer P. Enzyme-catalyzed hydrolysis of dentin adhesives containing a new urethane-based trimethacrylate monomer. J Biomed Mater Res Part B: Appl Biomater. 2009;91B: 562-571.

114. Park J, Ye Q, Topp EM, Kieweg SL, Spencer P. Effect of photoinitiator system and water content on dynamic mechanical properties of a light-cured bisGMA/HEMA dental resin. J Biomed Mater Res Part A. 2010;93(4):1245-1251.

115. Park JG, Ye Q, Topp EM, Misra A, Spencer P. Water sorption and dynamic mechanical properties of dentin adhesives with a urethanebased multifunctional methacrylate monomer. Dent Mater. 2009;25: 1569-1575.

116. Drummond JL. Degradation, fatigue, and failure of resin dental composite materials. J Dent Res. 2008;87(8):710-719.

\section{Publish your work in this journal}

Clinical, Cosmetic and Investigational Dentistry is an international, peer-reviewed, open access, online journal focusing on the latest clinical and experimental research in dentistry with specific emphasis on cosmetic interventions. Innovative developments in dental materials, techniques and devices that improve outcomes and patient satisfac- tion and preference will be highlighted. The manuscript management system is completely online and includes a very quick and fair peerreview system, which is all easy to use. Visit http://www.dovepress. com/testimonials.php to read real quotes from published authors.

Submit your manuscript here: http://www.dovepress.com/clinical-cosmetic-and-investigational-dentistry-journal 